九州大学学術情報リポジトリ

Kyushu University Institutional Repository

\title{
The Efficiency of Hybridization and Seed Production in Musa spp
}

CHANG, Shu-Fen

Chiayi Agricultural Experiment Branch, Taiwan Agricultural Research Institute, COA

YEN, Yung-Fu

Department of BioAgricultural Science, National Chiayi University

MIYAJIMA, Ikuo

Institute of Tropical Agriculture, Kyushu University

HUANG, Kuang-Liang

Department of Horticultural Science, National Chiayi University

https://doi.org/10.5109/2339043

出版情報：九州大学大学院農学研究院紀要. 64 (2)，pp. 169-176，2019-09-02. Faculty of Agriculture, Kyushu University

バージョン :

権利関係 : 


\title{
The Efficiency of Hybridization and Seed Production in Musa spp
}

\author{
Shu-Fen CHANG ${ }^{1,2}$, Yung-Fu YEN ${ }^{3}$, Ikuo MIYAJIMA ${ }^{4}$, and Kuang-Liang HUANG ${ }^{2 *}$ \\ Institute of Tropical Agriculture, Kyushu University, \\ Fukuoka 819-0395, Japan \\ (Received April 8, 2019 and accepted May 8, 2019)
}

\begin{abstract}
In this study, Musa species and cultivars with different ploidy levels and genomic constitutions were hybridized to estimate the efficiency of the hybridization process and the yield of hybrid seeds. The findings are as follows. The hybridization of 'Dwarf Cavendish' (a triploid) as the female parent with the pollen of Musa balbisiana (a species of wild banana) produced few hybrid seeds, and that of 'Pei Chiao' as the female parent with the wild banana yielded no hybrid seed. The hybridization between 'Monkey' and the pollen of diploid wild bananas had a seed-set rate of $8 \%-12 \%$ and produced 1-19 hybrid seeds. The hybridization between 'Pelipia' and the pollen of diploid wild bananas had a seed-set rate of $6 \%-50 \%$. The hybridization of 'Pelipia' with $M$. balbisiana produced 1-219 hybrid seeds, 12-244 with M. itinerans var. formosana and 1-14 with $M$. textilis. The hybridization of $M$. balbisiana with $M$. itinerans var. formosana as the male parent (rather than as the female parent) produced seeds. Some of the hybrid seeds from the hybridization of triploid cultivars with the pollen of wild diploids were irregular or deformed in appearance. The hybridization of triploid cultivars with wild diploids as female parents produced more hybrid seeds, most of which were normal in appearance and some of them contained (a) no embryo or endosperm, (b) deformed embryos and no endosperm, or (c) deformed embryos and endosperms. Accordingly, the production of hybrid seeds does not necessarily indicate successful hybridization. The findings of this study may inform the selection of hybrid parents and banana breeding.
\end{abstract}

Key words: Musa spp., banana, hybridization, hybrid seed

\section{INTRODUCTION}

Bananas and plantains (Musa spp.) are an important crop in subtropical zones and have a worldwide production of approximately 100 million tons per year (HeslopHarrison, 2011). Most Musa cultivars are sterile and produce seedless fruits through parthenocarpy. Cultivated Musa hybrids and species are mostly triploid; only a few of them are diploid and tetraploid. The genetics and sterility of bananas and plantains cause difficulty with developing new varieties through hybridization (Heslop-Harrison and Schwarzacher, 2007). Banana cultivars are derived from intra- and inter-specific hybridization between $M$. acuminata Colla (AA) and $M$. balbisiana Colla (BB) (Simmonds and Shepherd, 1955). The earliest edible bananas are diploids that have evolved through the development of sterility and parthenocarpy of $M$. acuminata (Valmayor et al., 2000). Pollefeys et al. (2004) collected wild seedless bananas and parthenocarpic hybrids and mutants from various sources, domesticating them to produce seedless cultivars that are diploid ( $\mathrm{AA}$ and $\mathrm{AB}$ ), triploid ( $\mathrm{AAA}, \mathrm{AAB}$, and $\mathrm{ABB}$ ), and tetraploid (AAAA, $\mathrm{AAAB}, \mathrm{AABB}$, and ABBB). Worldwide, there are over 1,000 domesticated

\footnotetext{
Chiayi Agricultural Experiment Branch, Taiwan Agricultural Research Institute, COA, Chiayi 60014, Taiwan, Republic of China

2 Department of Horticultural Science, National Chiayi University, Chiayi 60004, Taiwan, Republic of China

Department of BioAgricultural Science, National Chiayi University, Chiayi 60004, Taiwan, Republic of China

${ }^{4}$ Institute of Tropical Agriculture, Kyushu University, Fukuoka 819-0395, Japan

* Corresponding author: (Email: klhuang@mail.ncyu.edu.tw)
}

Musa cultivars with high genetic diversity (HeslopHarrison and Schwarzacher, 2007).

Farmers propagated, grew, and cropped parthenocarpic, high-yielding, and disease-resistant banana plants during the first several millennia of banana cropping; undertook field trials of numbers of progeny during the twentieth century in which different species were crossed and the optimum progeny were selected; and have improved crops since the twenty-first century by using genetic maps and DNA markets to identify useful variant alleles of genes, conduct recombination between desirable traits, and combine different resistance genes and accelerate their selection (Heslop-Harrison, 2011). Many innovative techniques have been developed to facilitate plant breeding-e.g., micropropagation, anther culture, in vitro selection, embryo rescue, somaclonal variation, and somatic hybridization and transformation (Karp, 1995). Breeding Musa through mutation compensates for the weaknesses of existing Musa cultivars (Heslop-Harrison and Schwarzacher, 2007); for example, chemical mutagens can be used to induce mutations in the Highgate cultivar (AAA) for tolerance to Fusarium oxysporum f. sp. cubense (Bhagwat and Duncan, 1998). Combining both sexual and asexual reproduction systems might be the optimal strategy to increase the diversity of vegetative reproductive crops, such as bananas, with desirable traits (Uma and Arun, 2016).

Crucial targets of Musa spp. breeding include resistance to pathogens, diseases, and pests, short life cycles, low plant heights, high production, parthenocarpy, and species quality (Ortiz and Swennen, 2014). The genetic resources of wild bananas are regarded as a treasury database for providing useful resistance traits that can 
be effectively applied in crop modification (Padmesh et al., 2012). M. acuminate has many subspecies, among which hybrid cultivars are studied through cell biology; all diploid cultivars express hybridization at one or more translocations (Lanaud et al., 1992). Wild Musa spp. and related species not only provide natural introgression, but also increase the diversity of bananas (Uma and Arun, 2016).

Banana is both monoecious (containing both male and female reproductive organs) and dichogamous (temporal and female organs mature before the male organs) (Fortescue and Turner, 2011). The high sterility of Musa diploids and triploids renders it difficult to breed plantains and bananas through hybridization; some banana cultivars have sterile pollen (Ortiz, 1995). The existence of $2 n$ pollen in diploid species suggests the involvement of unilateral sexual polyploidization ( $2 n \times$ $n$ ) in the origin of triploid Musa species (Ortiz, 1997b). Goigoux et al. (2013) assessed the pollen fertility of both diploid and doubled-diploid of Mlalis (as donor of diploid gametes) that were treated with chromosome doubling. Pollen viability and count vary between Musa cultivars; diploid Musa species produce more viable pollen than do triploid Musa species; and tetraploid Musa species have the lowest pollen viability of the three (Fortescue and Turner, 2004). Triploid female fertile clones can be crossed with male fertile, diploid wild, or cultivated accessions to improve plantains and bananas (Oselebe et al., 2014). Plantains and bananas are improved by crossing heterogenomic triploid accessions ( $\mathrm{AAB}$ and $\mathrm{ABB}$ ) with homogenomic diploid accessions (AA and BB) (Rowe 1984). Triploid-diploid crosses between plantains and banana produce diploid, triploid, and tetraploid hybrids (Ortiz, 1997a).

Minimizing infertility barriers by crossing triploid landraces with wild diploids or tetraploids with diploids to produce sterile triploids and inter- and intra-specific hybrids can improve triploid Musa species with desired traits (Pillay et al., 2002). Assessing the number, quality, and embryo rescue rates of hybrid seeds can enhance the efficiency of banana breeding (Ssebuliba $e t$ al., 2006). In this study, Musa species and cultivars with different ploidy levels and genomic constitutions were hybridized to assess the efficiency of the hybridization and the yield of hybrid seeds.

\section{MATERIALS AND METHODS}

\section{Plant materials}

This study used 28 Musa species and cultivars (materials from four M. acuminata and one M. balbisiana, 21 intra- or interspecific hybrids of $M$. acuminata and $M$. balbisiana, one species of $M$. itinerans var. formosana, and one species of $M$. textilis) cultivated in a banana germplasm garden managed by the Taiwan Agricultural Research Institute (Chiayi branch) (Table 1 ). The garden is located at the geographic coordinates of $23^{\circ} 48^{\prime} 43^{\prime \prime} \mathrm{N}$ and $120^{\circ} 46^{\prime} 80^{\prime \prime} \mathrm{E}$, with an altitude of $33 \mathrm{~m}$, an average annual temperature of $23^{\circ} \mathrm{C}$, and an average annual rainfall of $2000 \mathrm{~mm}$.

\section{Cross-pollination combinations}

Twenty-one Musa species and cultivars-4 diploids (AA, $\mathrm{AB}$, and $\mathrm{BB}), 15$ triploids ( $\mathrm{AAA}, \mathrm{AAB}$, and $\mathrm{ABB}$ ), one species of $M$. itinerans var. formosana, and one species of $M$. textilis-were used as female parents. Fourteen Musa species and cultivars-5 diploids (AA and $\mathrm{BB}$ ), 7 triploids (AAA, ABB, and $\mathrm{BBB}$ ), one species of $M$. itinerans var. formosana, and one species of $M$. textilis-were used as male parents (or pollen sources). Cross-pollination was conducted for each tier (hand) of female inflorescences (Table 2). Cross-pollinated female inflorescences were packaged to prevent contamination.

\section{Hybridization results and the examination of hybrid seeds}

The mature fruits of Musa species and cultivars were harvested following cross pollination; both the number of hybrids between Musa species and cultivars and the seed-set rate of the hybridization were estimated. The seeds extracted from fruits were examined and the number of seeds and their development patterns were analyzed. The section profiles of hybrid seeds were observed using a stereo microscope.

\section{RESULTS}

\section{Seed sets produced from hybridization between Musa species and cultivars}

Table 3 presents the results of different hybrids between Musa species and cultivars. Seeds were obtained through hybridization using $M$. balbisiana (BB), 'Dwarf Cavendish' (AAA), 'Monkey' (ABB), 'Pelipia' (ABB), $M$. itinerans var. formosana (ABB), and $M$. textilis (ABB) as female parents. The male parents were $M$. acuminata (AA), 'Calcultair 124' (AA), M. balbisiana (BB), M. itinerans var. formosana (BB), M. textilis (BB).

Table 2 shows the seed-set rates of different hybrids between Musa species and cultivars. The seed-set rate was $100 \%$ for the hybridization of $M$. balbisiana (female parent) with $M$. acuminate, 20\% with 'Calcultair 124', $43 \%$ with $M$. balbisiana, $75 \%$ with $M$. itinerans var. formosana, and 50\% with $M$. textilis. The seed-set rate for the hybridization of 'Dwarf Cavendish' (female parent) was $33 \%$ with $M$. balbisiana. The seed-set rate for the hybridization of 'Monkey' (female parent) was 10\% with both 'Calcultair 124' and M. balbisiana, 8\% with $M$. itinerans var. formosana, and $12 \%$ with $M$. textilis. The seed-set rate for the hybridization of 'Pelipia' (female parent) was $9 \%$ with $M$. balbisiana, $6 \%$ with $M$. itinerans var. formosana, and 50\% with $M$. textilis. The seed-set rate for the hybridization of $M$. itinerans var. formosana (female parent) was 100\% with 'Calcultair 124', 17\% with M. itinerans var. formosana, and $11 \%$ with M. textilis. The seed-set rate for the hybridization of $M$. textilis (female parent) was $100 \%$ with $M$. balbisiana, M. itinerans var. formosana, and M. textilis.

\section{Hybrid seeds produced}

Table 3 also summarizes the number of seeds pro- 
Table 1. Plant materials of the genus Musa used in this study

\begin{tabular}{|c|c|c|c|c|c|}
\hline No. & Accession ID ${ }^{\text {a }}$ & Species/hybrid & Genome & Common name & Abbreviation \\
\hline 1 & 00264380 & M. acuminata & $\mathrm{AA} \mathrm{w}^{\mathrm{c}}$ & Musa acuminata & ACU \\
\hline 2 & $-{ }^{b}$ & M. acuminata & $\mathrm{AA}$ & Calcultair 124 & CAL \\
\hline 3 & 00264568 & M. acuminata & $\mathrm{AA} \mathrm{CV}^{\mathrm{c}}$ & Cultivar Rose & $\mathrm{CRO}$ \\
\hline 4 & 00105288 & M. acuminata & $\mathrm{AA}$ & Sucrier & SUC \\
\hline 5 & 00105297 & $\begin{array}{l}\text { M. acuminata } \times \\
\text { M. balbisiana }\end{array}$ & $\mathrm{AB}$ & Ney Poovan & NPO \\
\hline 6 & 00105304 & M. balbisiana & $B B w^{d}$ & Musa balbisiana & BAL \\
\hline 7 & 00105411 & M. acuminate (Triploid) & AAA & Dwarf Cavendish & DCA \\
\hline 8 & 00264479 & M. acuminate (Triploid) & AAA & Gctcv-119 & GCT \\
\hline 9 & 00105466 & M. acuminate (Triploid) & $\mathrm{AAA}$ & Giant Cavendish & GCA \\
\hline 10 & 00264317 & M. acuminate (Triploid) & AAA & Manang & MAN \\
\hline 11 & 00106025 & M. acuminate (Triploid) & AAA & Pei Chiao & $\mathrm{PCH}$ \\
\hline 12 & 00264488 & M. acuminate (Triploid) & $\mathrm{AAA}$ & TC1-229 & TC1 \\
\hline 13 & 00105813 & M. acuminate (Triploid) & AAA & Valery & VAL \\
\hline 14 & 00264577 & M. acuminate (Triploid) & $\mathrm{AAA}$ & Yangambi KM5 & YAN \\
\hline 15 & 00106043 & $\begin{array}{l}\text { M. acuminata } \times \\
\text { M. balbisiana (Triploid) }\end{array}$ & $\mathrm{AAB}$ & Assam & ASS \\
\hline 16 & 00264737 & $\begin{array}{l}\text { M. acuminata } \times \\
\text { M. balbisiana (Triploid) }\end{array}$ & $\mathrm{AAB}$ & Tibok & TIB \\
\hline 17 & 00264835 & $\begin{array}{l}\text { M. acuminata } \times \\
\text { M. balbisiana (Triploid) }\end{array}$ & $\mathrm{ABB}$ & Ice Cream & ICR \\
\hline 18 & 00263892 & $\begin{array}{l}\text { M. acuminata } \times \\
\text { M. balbisiana (Triploid) }\end{array}$ & $\mathrm{ABB}$ & Klue Namwa Khau & KNK \\
\hline 19 & 00263909 & $\begin{array}{l}\text { M. acuminata } \times \\
\text { M. balbisiana (Triploid) }\end{array}$ & $\mathrm{ABB}$ & Medine & MED \\
\hline 20 & 00264844 & $\begin{array}{l}\text { M. acuminata } \times \\
\text { M. balbisiana (Triploid) }\end{array}$ & $\mathrm{ABB}$ & Monkey & $\mathrm{MON}$ \\
\hline 21 & 00264853 & M. balbisiana (Triploid) & $\mathrm{ABB}$ & Nibah & NIB \\
\hline 22 & 00264335 & $\begin{array}{l}\text { M. acuminata } \times \\
\text { M. balbisiana (Triploid) }\end{array}$ & $\mathrm{ABB}$ & Pelipia & PEL \\
\hline 23 & 00263927 & $\begin{array}{l}\text { M. acuminata } \times \\
\text { M. balbisiana (Triploid) }\end{array}$ & $\mathrm{ABB}$ & Pisang Awak & PAW \\
\hline 24 & 00264559 & $\begin{array}{l}\text { M. acuminata } \times \\
\text { M. balbisiana (Triploid) }\end{array}$ & $\mathrm{ABB}$ & Pisang Nangka & PNA \\
\hline 25 & 00264899 & $\begin{array}{l}\text { M. acuminata } \times \\
\text { M. balbisiana (Triploid) }\end{array}$ & $\mathrm{ABB}$ & Pitogo & PIT \\
\hline 26 & 00264826 & M. balbisiana (Triploid) & $\mathrm{BBB}$ & Cooking & $\mathrm{COO}$ \\
\hline 27 & 00105242 & M. itinerans & 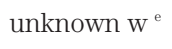 & Formosana & FOR \\
\hline 28 & 00105206 & M. textilis & $\mathrm{TT}^{\mathrm{f}}$ & Abaca & $\mathrm{ABA}$ \\
\hline
\end{tabular}

${ }^{a}$ Accession ID was based on the National Plant Genetic Resources Center of Taiwan Agricultural Research Institute

${ }^{\mathrm{b}}$ No Accession ID

${ }^{\mathrm{c}} M$. acuminate $A A w$ wild type, $A A c v$ cultivar

${ }^{\mathrm{a}} M$. balbisiana $B B w$ wild type

${ }^{\mathrm{e}} M$. itinerans diploid wild type

${ }^{\mathrm{f}} M$. textilis diploid wild type

duced from different hybrids between Musa species and cultivars. Hybridizing 'Dwarf Cavendish' as the female parent with the pollen of $M$. balbisiana produced one hybrid seed. Two of the hybrids between 'Monkey' (female parent) and 'Calcultair 124' produced 4 and 7 hybrid seeds. The hybridization of 'Monkey' (female parent) produced 1-7 hybrid seeds with $M$. balbisiana, 2-19 hybrid seeds with $M$. itinerans var. formosana, and one hybrid seed with $M$. textilis. The hybridization of 'Pelipia' (female parent) produced 1-219 hybrid seeds with $M$. balbisiana, 12-217 hybrid seeds with M. itinerans var. formosana, and 1-14 hybrid seeds with $M$. textilis. Two of the hybrids between $M$. balbisiana (female parent) with $M$. acuminata produced 68 and 147 hybrid seeds. The hybridization of M. balbisiana (female parent) produced 182 hybrid seeds with 'Calcultair 124', 21-303 hybrid seeds with $M$. balbisiana, 3-3297 hybrid seeds with $M$. itinerans var. formosana, and 
Table 2. Number of hybrid seed sets from different hybrids between Musa species and cultivars

\begin{tabular}{|c|c|c|c|c|c|c|c|c|c|c|c|c|c|c|}
\hline$+910^{x}$ & $\mathrm{ACU}$ & CAL & $\mathrm{CRO}$ & SUC & BAL & GCA & MAN & YAN & MED & NIB & PAW & $\mathrm{COO}$ & FOR & $\mathrm{ABA}$ \\
\hline CRO & $-{ }^{\mathrm{a}}$ & $1(0)$ & - & - & $1(0)$ & - & - & - & - & - & - & - & $1(0)$ & $2(0)$ \\
\hline SUC & $3^{b}(0)^{c}$ & $5(0)$ & - & - & $28(0)$ & - & - & - & - & - & - & - & $24(0)$ & $4(0)$ \\
\hline NPO & $4(0)$ & $6(0)$ & $1(0)$ & $1(0)$ & $14(0)$ & $1(0)$ & $1(0)$ & - & - & - & - & - & $16(0)$ & $9(0)$ \\
\hline BAL & $2(100)$ & $5(20)$ & $1(0)$ & - & $7(43)$ & - & $1(0)$ & - & - & - & $1(0)$ & $2(0)$ & $4(75)$ & $10(50)$ \\
\hline DCA & - & $2(0)$ & - & - & $3(33)$ & - & - & - & - & - & - & - & $2(0)$ & $2(0)$ \\
\hline GCA & - & - & - & - & $12(0)$ & - & - & - & - & - & - & - & $13(0)$ & - \\
\hline GCT & - & $1(0)$ & - & - & $2(0)$ & - & - & - & - & - & - & - & $1(0)$ & $1(0)$ \\
\hline $\mathrm{PCH}$ & $14(0)$ & $13(0)$ & $4(0)$ & $1(0)$ & $60(0)$ & $6(0)$ & - & - & - & $3(0)$ & - & $1(0)$ & $50(0)$ & $9(0)$ \\
\hline $\mathrm{TC} 1$ & - & $1(0)$ & - & - & $2(0)$ & - & - & - & - & - & - & - & $1(0)$ & $2(0)$ \\
\hline VAL & $2(0)$ & - & $1(0)$ & - & - & - & $2(0)$ & - & - & - & - & - & - & $1(0)$ \\
\hline ASS & - & $4(0)$ & - & - & $2(0)$ & - & - & - & - & - & - & - & - & - \\
\hline TIB & $2(0)$ & $2(0)$ & - & - & $19(0)$ & $1(0)$ & - & - & - & $1(0)$ & - & - & $19(0)$ & $3(0)$ \\
\hline ICR & - & $1(0)$ & - & - & $1(0)$ & - & - & - & - & - & - & - & $2(0)$ & $3(0)$ \\
\hline KNK & $2(0)$ & $2(0)$ & - & - & $2(0)$ & - & - & - & - & - & - & - & - & $4(0)$ \\
\hline MED & $1(0)$ & $1(0)$ & $1(0)$ & - & $2(0)$ & - & - & - & - & - & - & - & $2(0)$ & $1(0)$ \\
\hline MON & $17(0)$ & $21(10)$ & - & - & $41(10)$ & $6(0)$ & - & $1(0)$ & - & $1(0)$ & - & - & $48(8)$ & $25(12)$ \\
\hline PEL & $7(0)$ & $10(0)$ & - & - & $65(9)$ & $4(0)$ & - & - & $1(0)$ & $1(0)$ & - & - & $62(6)$ & $12(50)$ \\
\hline PIT & - & $2(0)$ & - & - & - & - & - & - & - & - & - & - & $2(0)$ & $2(0)$ \\
\hline PNA & - & $1(0)$ & - & - & $1(0)$ & - & - & - & - & - & - & - & $1(0)$ & $2(0)$ \\
\hline FOR & - & $1(100)$ & $1(0)$ & $1(0)$ & $7(0)$ & - & - & - & - & - & - & $3(0)$ & $6(17)$ & $9(11)$ \\
\hline $\mathrm{ABA}$ & - & $1(0)$ & - & - & $2(100)$ & - & - & - & - & - & - & - & $2(100)$ & $2(100)$ \\
\hline
\end{tabular}

${ }^{\text {a }}$ No hybridization

${ }^{\mathrm{b}}$ Number of tiers of inflorescence of hybridized female flowers

${ }^{\text {c }}$ Percentage of seed sets from hybridization

Table 3. Number of seeds from hybridization between Musa species and cultivars

\begin{tabular}{|c|c|c|c|c|c|}
\hline 우 \} 0 ^ { \pi } $&{\mathrm{ACU}} &{\mathrm{CAL}} &{\mathrm{BAL}} &{\text { FOR }} &{\mathrm{ABA}} \\
{\hline \text { BAL }} &{2^{\text {a }}(147,68)^{\mathrm{b}}} &{1(182)} &{3(303,21,30)} &{3(5,3297,3)} &{5(863,6,306,175,29)} \\
{\hline \text { DCA }} &{-{ }^{c}} &{0} &{1(1)} &{0} &{0} \\
{\hline \text { MON }} &{0} &{2(4,7)} &{4(1,1,1,7)} &{4(4,19,2,12)} &{3(1,1,1)} \\
{\hline \text { PEL }} &{0} &{0} &{6(38,1,219,118,6,7)} &{4(25,217,244,12)} &{6(2,3,6,3,1,14)} \\
{\hline \text { FOR }} &{-} &{1(853)} &{0} &{1(506)} &{1(773)} \\
{\hline \mathrm{ABA}} &{-} &{0} &{2(275,3)} &{2(278,27)} &{2(69,83)} \\
$\hline
\end{tabular}

${ }^{a}$ Number of hands in hybrid seed sets

${ }^{\mathrm{b}}$ Number of seeds/hands

${ }^{\text {c }}$ No hybridization

6-863 hybrid seeds with $M$. textilis. The hybridization of $M$. itinerans var. formosana (female parent) produced 853 hybrid seeds with 'Calcultair 124', 506 hybrid seeds with $M$. itinerans var. formosana, and 773 hybrid seeds with $M$. textilis. Two of the hybrids between $M$. textilis (female parent) with $M$. balbisiana respectively produced 3 and 273 hybrid seeds. Two of the hybrids between $M$. textilis (female parent) with $M$. itinerans var. formosana produced 27 and 278 hybrid seeds. Two of the hybrids between $M$. textilis (female parent) with M. textilis produced 69 and 83 hybrid seeds.

\section{Appearance of hybrid seeds}

The analysis of the appearances of hybrid seeds from crosses between Musa species and cultivars revealed the following findings. Hybrid seeds from the hybridization of 'Dwarf Cavendish' (female parent) with M. balbisiana were normal in appearance (Fig. 1a). Those from the hybridization of 'Monkey' (female parent) with $M$. balbisiana were abnormal and spindleshaped in appearance (Fig. 1b). Those from the hybridization of 'Pelipia' (female parent) with $M$. textilis had a normal oval appearance (Fig. 1c). Those from the hybridization of $M$. balbisiana (female parent) with the pollen of 'Calcultair 124', M. acuminata, and M. textilis respectively appeared elliptical (Fig. 1d), oval or deformed and shriveled (Fig. 1e-g), and as a normal oval (Fig. 1h). Those from the hybridization of $M$. textilis (female parent) with $M$. balbisiana and $M$. itinerans var. formosana had a normal oval appearance (Fig. 1i and $1 \mathrm{j}$ ). Seeds from the self-pollination of 'Pelipia' contained embryos and endosperms (Fig 1k-l). The self- 
pollination of 'Calcultair 124' produced normal oval seeds with embryos and endosperms and abnormal flat seeds with degenerated embryos and without endosperms (Fig. 1m-p). The self-pollination of M. balbisiana produced normal oval seeds with embryos and endosperms (Fig. 1q-r). The self-pollination of $M$. itinerans var. formosana produced normal seeds with a flat oval appearance, embryos and endosperms, and immature seeds colored in translucent white (Fig. 1s-u). The self-pollination of $M$. textilis produced normal oval seeds with embryos and endosperms and abnormal seeds with a normal oval appearance and without embryos or endosperms (Fig. 1v-x).

The analysis of the sectional profiles of hybrid seeds from crosses between Musa species and cultivars yielded the following findings. Hybrid seeds from the hybridization of $M$. balbisiana (female parent) with 'Calcultair 124' contained either shriveled endosperms or no embryo and endosperm (Fig. 2a-c). Those from the hybridization of $M$. balbisiana with $M$. acuminata contained normal embryos and endosperms, deformed embryos and endosperms, or no embryo or endosperm

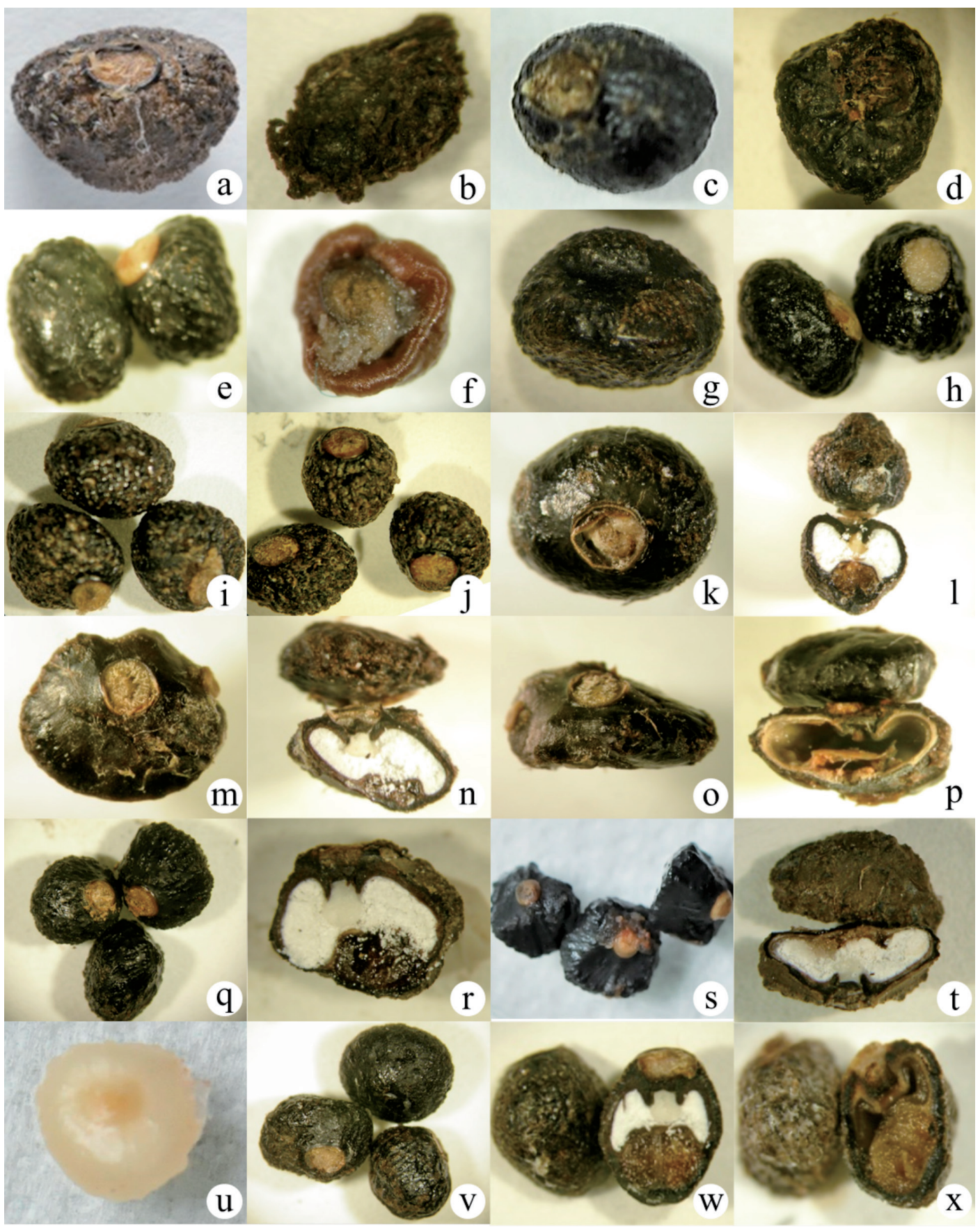

Fig. 1. Hybrid seeds of Musa spp. a. DCA x BAL; b. MON x BAL; c. PEL x ABA; d. BAL x CAL; e.,f. BAL x SUC; g. BAL x ACU; h. BAL x ABA; i. ABA x BAL; j. ABA x FOR; k.,l. PEL x PEL; m.-p. CAL x CAL; q.,r. BAL x BAL; s.-u. FOR x FOR ; v.-x. ABA x ABA.

(ABA: 'Abaca'; ACU: M. acuminata; BAL: M. balbisiana; CAL: 'Calcultair 124'; DCA: 'Dwarf Cavendish'; FOR: 'Formosana'; MON: 'Monkey'; PEL: 'Pelipita'; SUC: 'Sucrier') 


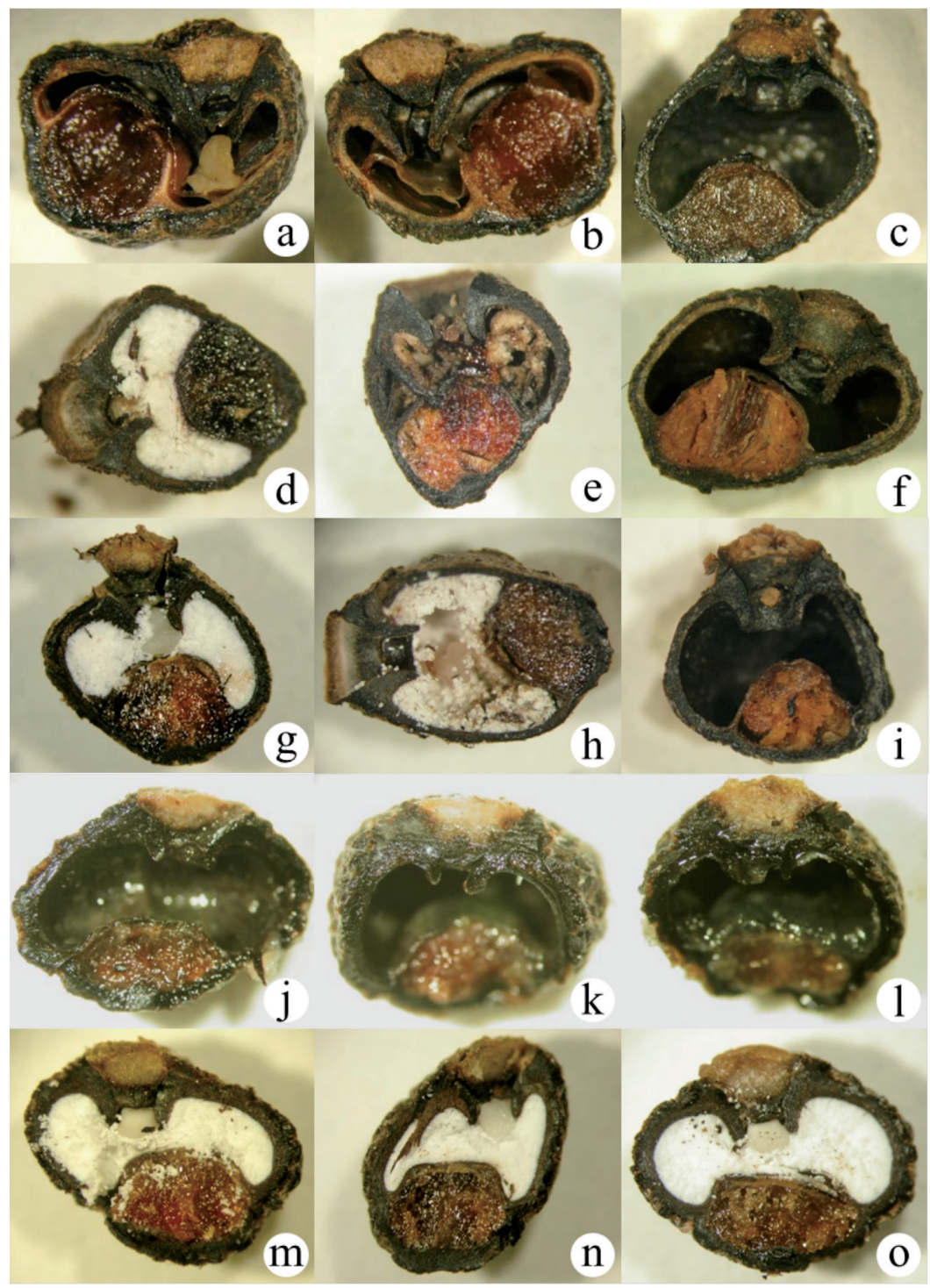

Fig. 2. Sectional profile of hybrid seeds of Musa spp. a.-c. BAL x CAL; d.-f. BAL x ACU; g. BAL x ABA; h.,i. BAL x FOR; j.-l. ABA x FOR; m.-O. ABA x BAL. (ABA: 'Abaca'; ACU: M. acuminata; BAL: M. balbisiana; CAL: 'Calcultair 124'; FOR: 'Formosana')

(Fig. 2d-f). Those from the hybridization of M. balbisiana with $M$. textilis contained embryos and endosperms (Fig. 2g). Those from the hybridization of $M$. balbisiana with $M$. itinerans var. formosana contained either embryos and underdeveloped endosperms or no embryo or endosperm (Fig. 2h-i). Those from the hybridization of $M$. textilis (female parent) with $M$. itinerans var. formosana contained no embryo or endosperm and merely translucent matters (Fig. 2j-1). Those from the hybridization of $M$. textilis with $M$. balbisiana contained embryos and endosperms (Fig. 2m-o).

\section{DISCUSSION}

The hybridization of Musa species and cultivars suggested that 'Dwarf Cavendish' (AAA), 'Monkey' (ABB), and 'Pelipia' (ABB) are female fertile clones that can be crossed with the wild species of $M$. balbisiana (BB), yielding seed-set rates of 33\%, 10\%, and 9\%, respectively. 'Dwarf Cavendish' had a low seed-set rate because it produced only one hybrid seed. Moreover, 'Giant Cavendish' and 'Pei Chiao' (the main cultivar indigenous to Taiwan) (Ko et al., 2009), both of which are Cavendish bananas, produced no hybrid seed (Tables 2 and 3). Edible bananas are parthenocarpic and typically seedless clones that are diploid, triploid or tetraploid; Cavendish clones (AAA) and $\mathrm{AAB}$ and $\mathrm{ABB}$ plantain groups have polyploidy, low fertility, and infertilitycharacteristics that limit the success of breeding programs (Shepherd, 1987).

Several triploid plantain and banana cultivars produced seeds after hand pollination with diploid parents. $\mathrm{ABB}$ cooking bananas had the highest rate of seed production, followed by AAB French plantains (Ortiz and Vuylsteke, 1995). The hybridization of 'Monkey' with 'Calcultair 124', M. balbisiana, M. itinerans var. for- 
mosana, and $M$. textilis had seed-set rates $10 \%$ (4-7 seeds), 10\%(1-7), 8\% (2-19 seeds), and 12\% (one seed), respectively. The hybridization of 'Pelipia' with M. balbisiana had a seed-set rate of 9\% (1-219 seeds), the hybridization of 'Pelipia' with $M$. itinerans var. formosana had a seed-set rate of 6\% (12-244 seeds), whereas the hybridization of 'Pelipia' with $M$. textilis had a seed-set rate of 50\% (1-14 seeds) (Tables 2 and 3). Triploid female clones can be crossed with male fertile, diploid wild, or cultivated accessions to improve plantains and bananas (Oselebe et al., 2014). Most edible bananas can be experimentally induced to yield seeds occasionally; breeding methods are assessed according to crosses between diploids, tetraploids and diploids, or triploids and diploids (Shepherd, 1987).

The hybridization of the wild species $M$. balbisiana (BB) with $M$. acuminata, 'Calcultair 124', M. itinerans var. formosana, and $M$. textilis had seed-set rates of 100\% (68-147 seeds), 20\% (182 seeds), $\quad 75 \%$ (3-3297 seeds), and 50\% (6-83 seeds), respectively. The hybridization of $M$. itinerans var. formosana with 'Calcultair 124' and M. textilis had seed-set rates of 100\% (853 seeds) and 11\% (773 seeds), respectively. Hybrids with the wild species $M$. balbisiana produced no seed. Notably, the hybridization of $M$. textilis with $M$. balbisiana, 'Calcultair 124', $M$. itinerans var. formosana had 100\% seed-set rates and produced seeds (Tables 2 and 3). Seasonal variation in $2 n$ pollen production correlates strongly with solar radiation, temperature, total pan evaporation, rainfall, and minimum relative humidity (Ortiz et al., 1998).

Between different sections of bananas, seeds vary slightly in appearance but are highly similar in structure and anatomy, and the outer integument of a Musa seed covers the micropylar and chalazal mass and the inner integument of the seed encompasses embryos and endosperms (Graven et al., 1996). In this study, slight differences were observed in seed appearance between the hybrids of the pollen of wild diploids with 'Dwarf Cavendish' (AAA), 'Monkey' (ABB), and 'Pelipia' (ABB); some hybrid seeds had a normal oval appearance, whereas others had an irregular or deformed and shriveled appearance (Fig. 1). Regarding the anatomical structure of hybrid seeds, some contained fully developed embryos and endosperms, some contained deformed embryos and deformed or shriveled endosperms, and some had a normal appearance but contained no embryo or endosperm (Fig. 2). Regarding the anatomical structure of hybrid seeds from the hybridization of $M$. balbisiana (BB) as the female parent, some contained fully developed embryos and endosperms, some contained embryos but no endosperm or underdeveloped endosperms, and some others had a normal appearance and contained either deformed embryos or no embryo or endosperm (Fig. 2). Regarding the anatomical structure of seeds from the hybridization of $M$. textilis (female parent) with $M$. balbisiana, the seeds contained normal embryos and endosperms. However, the hybridization of $M$. textilis with $M$. itinerans var. formosana produced seeds with- out embryos or endosperms (Fig. 2). Ssebuliba et al. (2006) studied hybrids from East African highland bananas, showing that although $72 \%$ of the seeds had a normal external appearance characterized by hard black integuments, only $59 \%$ contained embryos, of which $9 \%$ germinated. Their finding suggested that hard-seededness alone does not indicate the presence of an embryo and should not be used as a measure of seed fertility in East African highland bananas.

Interspecific and interploidy crosses are essential to producing Musa hybrids, with most of their hybrid seeds being immature and having low viability and germination rates under natural conditions (Ortiz and Vuylsteke, 1995). Therefore, the survival rates of hybrid seeds must be improved through micropropagation (Vuylsteke et al., 1990). Major factors in the success of breeding and hybridization of bananas include ploidy, genomic constitution, and male and/or female sterility. In the present study, the hybridization of $M$. balbisiana with $M$. itinerans var. formosana as the male parent, rather than the female parent, produced seeds. The findings of this study are expected to inform the utilization of banana germplasm and the improvement and breeding of banana.

\section{AUTHOR CONTRIBUTION}

1. Shu-Fen CHANG, proved the hybrid seed structure between Musa species or cultivars is not necessarily normal, and the parental selection affects the efficiency of hybridization.

2. Yung-Fu YEN, designed observational study of the appearance and sectional profile morphology of banana hybrid seeds, and offered suggestion for research.

3. Ikuo MIYAJIMA, offered advices on international tropical horticultural crops research for crossbreeding research, and revised paper and inspected final data.

4. Kuang-Liang HUANG, organized the research protocol through hybridization experiments of banana and managed lab process.

\section{REFERENCES}

Bhagwat, B. and E. J. Duncan 1998 Mutation breeding of banana cv. Highgate (Musa spp., AAA Group) for tolerance to Fusarium oxysporum f. sp. cubense using chemical mutagens. Sci. Hortic. 73: $11-22$

Fortescue, J. A. and D. W. Turner 2004 Pollen fertility in Musa: Viability in cultivars grown in Southern Australia. Aust. J. Agric. Res. 55: 1085-1091

Fortescue, J.A. and D.W. Turner 2011 Reproductive biology. In: M. Pillay and A. Tenkouano (eds). Banana Breeding-Progress and Challenges. pp. 145-180. London, UK

Goigoux S., F. Salmon and F. Bakry 2013 Evaluation of pollen fertility of diploid and doubled-diploid clones of Mlali and their potential use for banana breeding. Acta Hort. 986: 195-204

Graven, P., C.G. de Koster, J. J.Boon and F. Bouman 1996 Structure and macromolecular composition of the seed coat of the Musaceae. Ann. Bot. 77: 105-122

Heslop-Harrison, J. S. 2011 Genomic, banana breeding and superdomestication. Acta Hortic. 897: 55-62

Heslop-Harrison, J. S. and T. Schwarzacher 2007 Domestication, 
genomics and the future for banana. Ann. Bot. 100: 1073-1084

Karp, A. 1995 Somaclonal variation as a tool for crop improvement. Euphytica. 85: 295-302

Ko, W. H., C. C. Su, C. L. Chen and C. P. Chao 2009 Control of lethal browning of tissue culture plantlets of Cavendish banana cv. Formosana with ascorbic acid. Plant Cell, Tissue Organ Cult. 96: 137-141

Lanaud, C., H. T. du Montcel, M. P. Jolivot, J. C. Glaszmann and D. G. de Leon 1992 Variation of ribosomal gene spacer length among wild and cultivated banana. Heredity. 68: 147-156

Ortiz R. 1995 Musa genetics. In: S Gowen (ed) Bananas and Plantains. Chapman and Hall, London, UK. pp 84-109

Ortiz, R. 1997a Genetic and phenotypic correlations in plantainbanana euploid hybrids. Plant Breed. 116: 487-491

Ortiz, R. 1997b Occurrence and Inheritance of 2n Pollen in Musa. Ann. Bot. 79: 449-453

Ortiz, R. and D. Vuylsteke 1995 Factors influencing seed set in triploid Musa spp. L. and production of euploid hybrids. Ann. Bot. 75: 151-155

Ortiz, R. and R. Swennen 2014 From crossbreeding to biotechnology-facilitated improvement of banana and plantain. Biotechnol. Adv. 32: $158-169$

Ortiz, R., F. Ulburghs and J. U. Okoro 1998 Seasonal Variation of Apparent Male Fertility and 2n Pollen Production in Plantain and Banana. HortScience. 33: 146-148

Oselebe, H. O., C. V. Nnamani and E. Ikeh 2014 Pollen diversity, viability and floral structure of some Musa. Nig. J. Biotech. 27: $21-27$

Padmesh. P., S. Mukunthakumar, P. S. Vineesh, R. Skaria, K. Hari Kumar and P. N. Krishnan 2012 Exploring wild genetic resources of Musa acuminata Colla distributed in the humid forests of southern Western Ghats of peninsular India using ISSR markers. Plant Cell Rep. 31: 1591-1601
Pillay, M., A. Tenkouano, J. Hartman 2002 Future challenges in Musa breeding. In: Kang, M. S. (eds), Crop Improvement: Challenges in the Twenty-First Century. Food Products Press Inc., NY

Pollefeys, P., S. Sharrock and E. Arnaud 2004 Preliminary analysis of the literature on the distribution of wild Musa species using MGIS and DIVA-GIS. International Network for the Improvement of Banana and Plantain. (INIBAP), Montpellier, France. 68pp

Rowe, P. 1984. Breeding bananas and plantains. Plant Breed. Rev. 2: 135-155.

Simmonds, N. W. and K. Shepherd 1955 The taxonomy and origins of the cultivated bananas. Bot. J. Linn. Soc. 55: 302-312

Shepherd, K. 1987 Banana breeding-past and present. Acta Hortic. 196: 37-43

Ssebuliba, R., D. Talengera, D. Makumbi, P. Namanya, A. Tenkouano, W. Tushemereirwe and M. Pillay 2006 Reproductive efficiency and breeding potential of East African highland (Musa AAA-EA) bananas. Field Crops Res. 95: 250-255

Uma, S. and K. Arun 2016 Understanding the diversity and reproductive biology of banana-for improvement through basic research. Acta Hortic. 1114: 1-12

Valmayor, R. V., S. H. Jamaluddin, B. Silayoi, S. Kusumo, L. D. Danh, O. C. Pascua and R. R. C. Espino. (eds.) 2000 Banana cultivar names and synonyms in Southeast Asia. International Network for the Improvement of Banana and Plantain. (INIBAP), Montpellier, France. 28pp

Vuylsteke, D., R. Swennen, E. A. De Langhe 1990 Tissue culture technology for the improvement of African plantains. In: Fullerton, R. A., Stover, R. H. (eds.). Sigatoka Leaf Spot Diseases of Banana. Proc. Intl. Wksp. San Jose, Costa Rica. 28 March-1 April 1989. International Network for the Improvement of Banana and Plantain, Montpellier, France, pp. 316-337 